\title{
Publisher Correction: Quasinormal modes and horizon area quantisation in Loop Quantum Gravity
}

\author{
Saulo Carneiro ${ }^{1,2}$ (D) Cássio Pigozzo ${ }^{1}$ (D)
}

Published online: 5 March 2022

(c) The Author(s), under exclusive licence to Springer Science+Business Media, LLC, part of Springer Nature 2022

\section{General Relativity and Gravitation (2022) 54:20 https://doi.org/10.1007/s10714-022-02905-8}

The publication of this article unfortunately contained a mistake. The assignment of the affiliations was incorrect. The corrected affiliations are given below.

Saulo Carneiro ${ }^{1,2}$. Cássio Pigozzo ${ }^{1}$.

${ }^{1}$ Instituto de Física, Universidade Federal da Bahia, Salvador, BA 40210-340, Brazil

${ }^{2}$ PPGCosmo, CCE, Universidade Federal do Espírito Santo, Vitória, ES 29075-910, Brazil

The original article has been corrected.

Publisher's Note Springer Nature remains neutral with regard to jurisdictional claims in published maps and institutional affiliations.

The original article can be found online at https://doi.org/10.1007/s10714-022-02905-8.

$\otimes \quad$ Saulo Carneiro

saulo.carneiro.ufba@gmail.com

1 Instituto de Física, Universidade Federal da Bahia, Salvador, BA 40210-340, Brazil

2 PPGCosmo, CCE, Universidade Federal do Espírito Santo, Vitória, ES 29075-910, Brazil 